\title{
DYNAMICS OF STRESS LABORATORY FINDINGS AND THEIR RELATION TO PSYCHOEMOTIONAL STATE DURING REGIONAL ANESTHESIA IN PATIENTS WITH LOWER LIMBS INJURIES
}

\author{
Elina Korobko \\ Department for Traumatology, Anesthesiology and Military Surgery \\ Kharkiv Medical Academy of Postgraduate Education \\ 58 Amosova str., Kharkiv, Ukraine, 61176 \\ elinakorobko87@gmail.com
}

\begin{abstract}
The choice of an adequate method of anesthesia for surgical treatment of lower limbs injuries remains a critical task today. Each method applied in this treatment has its advantages and disadvantages. In recent years, regional anesthesia has been the preferential method.

The aim of the study. To study the stress laboratory findings and their relation to the patients' psychoemotional state in perioperative period while performing regional and combined anesthesia.

Material and methods. It was studied 60 patients aged 18-59 years, who underwent metal osteosynthesis operations due to lower limbs injuries. Surgical treatment was performed under regional anesthesia and regional anesthesia followed by sedation. The patients of both groups were conducted heamodynamics monitoring and determined the intensity of pain in accordance with visual analogue scale and stress indicators with a laboratory method. The psychoemotional state was assessed with the Spielberger-Hanin anxiety scale.

Results. According to the study it was determined, that in patients, who were planned to have surgery, significant psychoemotional stress and stress concentration of hormones in the blood and their interrelation was discovered. Patients about before surgery had a relationship between situational anxiety and cortisol $r=0.7 ; p=0.00006$ in group $I ; r=0.6 ; p=0.002$ in the second group. The relationship between VAS and cortisol $\mathrm{r}=0.5 ; \mathrm{p}=0.04$ in groups I and II. After surgery, the connection was in group I patients between situational anxiety and cortisol $r=0.4 ; p=0.02$; the relationship between insulin and the HOMA index r=0.5; $p=0.01$.

Conclusions. Before the operation, all patients revealed significant psychoemotional stress and stressful changes in the concentration of hormones in the blood. Reliably pronounced dynamics of the indicators was with the use of combined conduction anaesthesia. Thus, the performed study allows to recommend combined regional anesthesia as the method of anesthesia choice, particularly in patients with high anxiety.
\end{abstract}

Keywords: regional anesthesia, lower limbs injury, pain intensity, psychoemotional state, biochemical markers of stress.

DOI: $10.21303 / 2504-5679.2020 .001365$

\section{Introduction}

A large number of surgeries for lower limbs injuries are performed all over the world and in our country, therefore their adequate anesthetic support remains a critical task. A lot of works have been dedicated to the issue of choice of the anesthesia method during these surgeries, the advantages and disadvantages of both general and regional anesthesia are described $[1,2]$. In recent years, the methods of regional anesthesia are preferred due to their sufficient level of pain control as well as economic efficiency [3, 4].

From the perspective of practical anesthesiology, an important factor when selecting the anesthesia method is probability of complications developing both during, and after surgery [5, 6]. Unfortunately, none of the anesthesia methods is deprived of adverse effects and events, however, most researchers indicate the relative safety of regional anesthesia while meeting the requirements of their implementation, adequate monitoring and consideration of counterindications [7, 8].

The analyses of the perioperative complications of anesthesia has been the subject of many works [9]. Most part of them is dedicated to the problems of organ dysfunctions, such as respiratory and heart failure, renal failure, intraintestinal dysfunction, etc. $[10,11]$. This is due to the fact that any arising organ failure leads to the worsening of the postoperative period, while the time spent by the patients in the intensive therapy unit and in the hospital increases, the mortality rate increases, 
the quality of life decreases $[12,13]$. At the same time, much smaller number of publications is dedicated to the problems of the patients' psychological state [14, 15]. The question arises, if psychoemotional stress, depression can be a complication of the perioperative period or if they are just patient's individual characteristics? This question can be unambiguously answered, that all significant deviations in the patient's psychological status, arising in the perioperative period, certainly, are complications and should not only be noted in the medical documentation, but also adequately evaluated and corrected. In the Standards of the European Society of Anesthesiologists the following sections are dedicated to the patients' psychological state: the indicators of psychometric assessment of quality of the postoperative recovery and scale of life quality, related to health [16, 17].

Thus, the large-scale implementation of the assessment methods of the patients' psychological state in perioperative period for different types of surgeries is a critical task of the modern anesthesiology. It will allow to carry out a differentiated choice of anesthesia method taking into account the patient's individual psychological characteristics and, thus, improve the course of the postoperative period.

The aim of the work. To study the stress laboratory findings and their relation to the patient's psychoemotional state in perioperative period while performing regional and combined anesthesia during surgeries for lower limbs injuries.

\section{Materials and methods}

60 patients, who underwent metal osteosynthesis operations due to lower limbs injuries, were included into the study on the base of Anesthesiology and Intensive Therapy Department of MNE of KhRC "Regional Clinical Traumatological Hospital” in 2017-2020 years.

The criteria for inclusion to the study were age 18-59 years; planned lower limbs surgery related to injuries; the duration of surgery more than 60 minutes, the type of anesthesia: regional anesthesia, regional anesthesia followed by sedation; anesthetic risk according to ASA - I-II; informed consent to participate in the study and understanding of the contents of psychometric techniques and VAS.

The criteria for exclusion from the study were diabetes mellitus, myocardial infarction, neurological disorders, respiratory diseases, visual and aural disorders, repeated surgery; the use of tranquilizers, antidepressants, nootropics; alcoholism, drug abuse; pain syndrome not related to the injury and surgery.

The study was conducted in accordance with the requirements of good clinical practice, the Council of Europe Convention on Human Rights and Biomedicine, the Helsinki Declaration of the World Medical Association and approved by the local ethics committee of the Kharkiv Medical Academy of Postgraduate Education (protocol No. 2, from 26.06.2020). All patients signed informed consent for participating in the clinical trial.

Depending on the anesthesia method the patients were divided into 2 groups: group I $(n=33)$ included the patients, who were operated on under conditions of regional anesthesia (the average age $40.4 \pm 1.8$ years); group II $(\mathrm{n}=27)$ included the patients, who were operated on under conditions of regional anesthesia followed by sedation with $1 \%$ profopol at target concentration $2 \mathrm{mg} / \mathrm{kg} / \mathrm{h}$ (the average age $40.0 \pm 2.1$ years).

Body mass ratio (BMR) in patients of group I was $26.3 \pm 0.8 \mathrm{~kg} / \mathrm{m}^{2}$ and in patients of group II $-26.4 \pm 0.7 \mathrm{~kg} / \mathrm{m}^{2}$. The patients of both groups did not differ from each other in anthropometric indexes $(\mathrm{p}>0.05)$.

All the patients underwent complex clinical laboratory examination and preoperative preparation.

Before surgery, patients received standard preventive premedication at the bedtime: per os Sibazon $10 \mathrm{mg}$.

When performing surgeries in patients of both groups, distal block of sciatic nerve with the posterior approach in popliteal space was applied. The sciatic nerve block was performed in combination with a "three-in-one" femoral nerve block. For identification of nerve trunks the «Stimuplex» electrostimulator was used. Puncturing was performed with a specific electrically secured needle «Stimuplex A», which allows to increase the accuracy of determining the localization of the 
nerve. As the needle approached the nerve trunk, the contraction of the associated muscle group was obtained in response to irritation by an electrical impulse. An adequate motor response was considered a plantar foot flexion. The nerve block in patients of both groups was carried out with $1 \%$ solution of lidocaine $800 \mathrm{mg}$ with an addition of epinephrine (1:200000), as an adjuvant.

The postoperative anesthesia was performed with non-steroidal anti-inflammatory drugs (dexketoprofen, at the patients' request).

BMR was determined according to the formula: $\mathrm{m} / \mathrm{h}^{2}$, where $\mathrm{m}$ is for mass of the body $(\mathrm{kg})$, $\mathrm{h}$ is for height $(\mathrm{m})$

The monitoring was carried out, which included control of the systolic blood pressure (SBP), diastolic pressure (DIA), cardiac rate (CR), electrocardiography and arterial oxygen percent saturation $\left(\mathrm{SpO}_{2}\right)$ with the help of monitor G3L («Heaco», United Kingdom), mean arterial pressure (MAP) was determined according to the formula: (2 (SBP)+DIA)/3, the indicators were recorded before surgery, at the traumatic stage and on the first day after surgery.

The intensity of pain was evaluated according to the visual analogue scale (VAS) before the surgery (stage 1) and in the first 24-hour period after the surgery (stage 3). The visual analogue scale represents a continuous scale in the form of a horizontal or vertical line $10 \mathrm{~cm}$ long and two extreme points "no pain" and "severe pain that you can only imagine" located on it.

In our study we used a specific ruler with a slider, in which we suggested the patient to indicate the intensity of the pain syndrome. The distance between the marks "No pain" and "Unbearable pain" was drawn on a coloured scale and is $10 \mathrm{~cm}$ long on one side and on the other side coloured symbols from blue to red according to the intensity of the pain syndrome were drawn. Based on the allocation of points the following classification is recommended: no pain (0 points), weak pain (1-4 points), moderate pain (4-6 points), severe pain (7-9 points), very severe pain (10 points).

The study of psychoemotional state included determining of the level of personal anxiety, which characterizes a stable tendency to perceive a wide range of situations as threatening, to respond to such situations with the anxiety state and a situational anxiety, which is characterized by tension, psychic tension, nervousness. The situational anxiety causes attention failure, sometimes it causes violation of fine coordination. These data were evaluated at three stages of the study: before the surgery (stage 1) and on the first day after surgery (stage 3) according to the Spielberger-Hanin scale, which was developed by an American psychologist Charles Spielberger in 1970 and adapted by Russian psychologist Yuriy Hanin in 1976.

The assessment methodology of the situational and personal anxiety determines the anxiety level based on the self-assessment scale (high, medium and low anxiety), it is carried out with two cards: one is for situational anxiety, the second one is for personal anxiety measuring.

The interpretation of indicators was determined by points:

- up to 30 points - low;

- 31-44 points - moderate;

- more than 45 points - high.

All laboratory tests were also recorded at three stages of the study: stage 1 - before surgery; stage 2 - at the traumatic stage and stage 3 on the first day after surgery.

Blood glucose measurement was evaluated with the glucose oxidase test by means of the "GLUCOSE SpineLab", Ukraine reagent kit.

Indicators of cortisol and insulin levels were determined with the immunoenzyme method by means of "Vector-Best-Ukraine" reagent kit.

Index HOMA (The Homeostatic Model Assessment), which displays the degree of insulin resistance, that depends on the stress reactions degree, was calculated by the formula:

$\mathrm{HOMA}=($ Glucose $(\mathrm{mmol} / \mathrm{l})) \times \operatorname{Insulin}(\mathrm{umol} / \mathrm{ml})) / 22,5$.

Cortisol-insulin correlation (C/I) was calculated by the formula:

$\mathrm{C} / \mathrm{I}=$ Cortisol (nmol/l)/Insulin (umol/ml). 
For statistical processing of the obtained data, the «SPSS Statistics 19.0» program was used. Parametric and nonparametric methods of statistics were used with the usage of Student's and Mann-Whitney criterion. To evaluate the relations between the indicators a correlation analyses was carried out with the usage of Spearman criterion.

\section{Results}

All surgical interferences were performed to young and middle-aged patients without significant concomitant pathology and with moderate risk of anesthesia (I-II in accordance with ASA). Therefore, the course of intra- and postoperative periods in patients passed without significant disturbances of vital organs. In patients of both groups, the nornodinamic type of blood circulation with an average blood pressure within the range of 90-110 $\mathrm{mm} \mathrm{Hg}$, normal gemoglobin oxygen saturation $\left(\mathrm{SpO}_{2} \geq 95 \%\right)$ and sufficient diuresis were noted intraoperatively. None of the examined patients needed additional measures of heamodynamic and respiratory support during surgery and in the early postoperative period.

The main differences that we discovered between the patients' groups, dealt with their psychoemotional state and laboratory stress markers. So, before surgery, the patients of both groups showed significant psychoemotional tension according to the Spielberger-Hanin scale, which can be explained both by the expectation of surgery and the damage associated with it, and by the presence of post-traumatic pain syndrome (Table 1).

Table 1

Anxiety indicators in patients of groups I-II at the stages of the study (Me [Q1; Q3]), points

\begin{tabular}{ccc}
\hline Measurement & $\begin{array}{c}\text { Group I } \\
(\mathbf{n = 3 3 )}\end{array}$ & $\begin{array}{c}\text { Group II } \\
(\mathbf{n = 2 7})\end{array}$ \\
\hline Situational anxiety before surgery & 49.5 & 46.0 \\
& {$[48.0 ; 50.0]$} & {$[44.0 ; 50.0]$} \\
Personal anxiety before surgery & 54.0 & 49.0 \\
& {$[51.0 ; 55.0]$} & {$[44.0 ; 56.0]$} \\
Situational anxiety after surgery & 41.0 & $34.0^{*}$ \\
& {$[40.0 ; 42.0]$} & {$[30.0 ; 38.0]$} \\
Personal anxiety after surgery & 45.0 & $34.5^{*}$ \\
\end{tabular}

Note: ${ }^{*}$ - significant difference between groups: $p<0.01$

In the early postoperative period, the indicators of situational and personal anxiety in the group of patients who underwent additional sedation were significantly lower $(\mathrm{p}<0.01)$.

Pain intensity indicators according to VAS in the patients before surgery were $5.2 \pm 0.1$ points in group I and 5.1 \pm 0.2 points in group II $(\mathrm{p}>0.05)$. In 24 hours after the surgery a decrease of the pain syndrome intensity was observed $3.7 \pm 0.1$ points in group I and $3.1 \pm 0.1$ points in group II $(p<0.05)$. It supports the fact that the mechanisms of nociception are implemented in numerous ways, thus deprivation of central routs of perception can be significant. Moreover, the emotional colouring of the situation during the survey plays a certain role, as the anxiety in general and the emotional tension accordingly in the patients of group II were lower.

Through laboratory studies of hormonal indicators of the stress response in patients of both groups, some well-known patterns were discovered and confirmed, which were evident as an increase of cortisol concentration in the blood plasma, cortisol/insulin correlation and the insulin resistance index HOMA (Table 2).

In the process of surgical interference under regional anesthesia the cortisol level was decreasing in both groups. This dynamics was more significant in group II compared to group I $(p<0.01)$. Thus, there was a tendency to decreasing in the dynamics of cortisol/insulin index to normal and subnormal values in both groups. 
Table 2

Hormonal reactions in perioperative period in patients of groups I-II (Me [Q1;Q3])

\begin{tabular}{|c|c|c|c|c|c|}
\hline \multirow{2}{*}{ Stage of the Study } & \multirow{2}{*}{ Groups } & \multicolumn{4}{|c|}{ Measurement } \\
\hline & & Cortisol, $\mathrm{nmol} / \mathbf{l}$ & Insulin, umol/ml & $\mathrm{C} / \mathbf{I}$ & HOMA \\
\hline \multirow{2}{*}{1} & $\mathrm{I}(\mathrm{n}=33)$ & $\begin{array}{c}630.3 \\
{[589.3 ; 655.6]}\end{array}$ & $\begin{array}{c}10.3 \\
{[8.6 ; 12.2]}\end{array}$ & $\begin{array}{c}59.8 \\
{[52.7 ; 68.2]}\end{array}$ & $\begin{array}{c}2.1 \\
{[1.9 ; 2.7]}\end{array}$ \\
\hline & II $(n=27)$ & $\begin{array}{c}657.7 \\
{[598.2 ; 691.9]}\end{array}$ & $\begin{array}{c}9.8 \\
{[8.3 ; 11.7]}\end{array}$ & $\begin{array}{c}67.0 \\
{[55.9 ; 85.1]}\end{array}$ & $\begin{array}{c}2.0 \\
{[1.9 ; 2.5]}\end{array}$ \\
\hline \multirow{2}{*}{2} & $\mathrm{I}(\mathrm{n}=33)$ & $\begin{array}{c}508.4 \\
{[498.8 ; 575.4]}\end{array}$ & $\begin{array}{c}8.5 \\
{[7.9 ; 10.6]}\end{array}$ & $\begin{array}{c}59.9 \\
{[53.2 ; 69.9]}\end{array}$ & $\begin{array}{c}2.2 \\
{[2.1 ; 2.5]}\end{array}$ \\
\hline & II $(n=27)$ & $\begin{array}{c}445.7 * * \\
{[399.5 ; 504.2]}\end{array}$ & $\begin{array}{c}7.3 \\
{[6.1 ; 10.4]}\end{array}$ & $\begin{array}{c}57.3 \\
{[45.5 ; 74.8]}\end{array}$ & $\begin{array}{c}1.6^{* *} \\
{[1.3 ; 2.2]}\end{array}$ \\
\hline \multirow{2}{*}{3} & $\mathrm{I}(\mathrm{n}=33)$ & $\begin{array}{c}478.3 \\
{[453.5 ; 500.5]}\end{array}$ & $\begin{array}{c}9.2 \\
{[8.5 ; 10.5]}\end{array}$ & $\begin{array}{c}51.6 \\
{[41.4 ; 56.1]}\end{array}$ & $\begin{array}{c}2.5 \\
{[2.2 ; 2.8]}\end{array}$ \\
\hline & II $(n=27)$ & $\begin{array}{c}368.6^{* *} \\
{[338.0 ; 400.3]}\end{array}$ & $\begin{array}{c}8.4^{*} \\
{[6.6 ; 10.0]}\end{array}$ & $\begin{array}{c}49.7 \\
{[35.9 ; 58.7]}\end{array}$ & $\begin{array}{c}1.6^{* *} \\
{[1.3 ; 2.2]}\end{array}$ \\
\hline
\end{tabular}

Note: ${ }^{*}-p<0.05$ by comparison to the group I at the third stage of the study; ${ }^{*}$ - accuracy of difference between groups $p<0.01$

The insulin resistance index HOMA in the patients of group I did not change significantly (Table 2), while in group II its decrease was noted (Table 2), which was significant compared to group I $(\mathrm{p}<0.01)$.

The glycemia level in patients of both groups was at the upper limit of normal which also indirectly characterizes the stress response in the patients without concomitant diabetes mellitus. In the initial state, the glucose concentration in the patients of group I was $5.1 \pm 0.1 \mathrm{mmol} / \mathrm{l}$, during the surgical interference it was $5.8 \pm 0.1 \mathrm{mmol} / 1$, the next 24 hours after surgery it was $5.9 \pm 0.1 \mathrm{mmol} / \mathrm{l}$, there were no differences at all stages of surgical treatment $(\mathrm{p}>0.05)$. In patients of group II similar results were obtained at all stages of the study $-5.1 \pm 0.1 \mathrm{mmol} / 1 ; 5.2 \pm 0.1 \mathrm{mmol} / \mathrm{l}$ and $4.9 \pm 0.1 \mathrm{mmol} / 1$, respectively ( $\mathrm{p}>0.05)$.

Thus, in patients of both groups in the perioperative period a significant psychoemotional reaction was discovered with the increase of situational and personal anxiety, an intense pain syndrome and specific "stress" reaction. While studying the relation between these indicators, some patterns were discovered.

In preoperative period in the patients of both groups a strong connection between the indicators of situational anxiety and the cortisol level in the blood plasma $(r=0.7 ; p=0.00006$ in group I and $\mathrm{r}=0.6 ; \mathrm{p}=0.002$ in group II) was discovered. Moderate relation was discovered between the indicators of pain intensity according to VAS and the cortisol concentration before the surgery in both groups $(\mathrm{r}=0.5 ; \mathrm{p}=0.004)$.

In the postoperative period in patients of group II there were no significant relations of the studied indicators. At the same time in patients of group I remained a moderate relation between the indicator of situational anxiety and the cortisol concentration in the blood $(\mathrm{r}=0.5 ; \mathrm{p}=0.01)$, insulin in the blood $(\mathrm{r}=0.4 ; \mathrm{p}=0.02)$ and the insulin resistant index HOMA $(\mathrm{r}=0.5 ; \mathrm{p}=0.01)$.

\section{Discussion}

Some researchers note that it is the patient's psychoemotional state that is one of the key in the implementation of many stressful reactions of the body, and also significantly affects the intensity of the pain syndrome and the associated treatment effectiveness. V. M. Zagurovsky [18]. Also, some authors claim in their studies that the psycho-emotional state before surgery is intense and requires psychological and pharmacological support. V. I. Strashnov et al. [19]. At the same time, the authors argue that the anesthetic risk in these conditions increases, due to the negative impact of emotional stress on the state of vital functions. A. Pinto et al. [20]. According to the results of the assessment of the hormonal profile, it was found that with a high and medium level of anxiety, the 
indicators of anxiety were higher. V. G. Syusyuk [21]. In the conducted studies, it was found that after surgery, the level of triviality was significantly lower and had a correlation with biochemical markers of stress. V. I. Kolomachenko [22].

Thus, our study demonstrated the importance of investigation of the patients' psychological state it the perioperative period since the significant emotional tension and the pain syndrome are related to a negative course of stress reaction that can affect the course of the perioperational period and the results of the treatment to a certain extent. In our opinion, the regional anesthesia combined with sedation can significantly minimize these effects and, therefore, it is the method of anesthesia choice for these surgeries, especially in patients with significant psychoemotional tension.

Study limitations. The studies were not conducted as a result of the identification of concomitant pathology of other organs and systems and as a result of patients refusing to study.

Prospects for further research. In the future, this study is possible with a larger sample of patients to more accurately obtain data. It is possible to expand the research phase with the expansion of the range of laboratory tests.

\section{Conclusions}

In patients who are planned to have surgeries on lower limbs, a significant psychoemotional tension and stress changes in the concentration of hormones in the blood, which are closely interrelated, were discovered in the perioperative period.

All patients showed a positive dynamics of the studied parameters, significantly more apparent when using combined regional anesthesia with sedation, so the indicator of the concentration of cortisol in the blood at the first stage in patients of group I was $630.3 \mathrm{nmol} / 1$ and $657.7 \mathrm{nmol} / 1$ in patients of group II, respectively, insulin indicators in group I were $10.3 \mathrm{umol} / \mathrm{ml}$ in group II this indicator was $9.8 \mathrm{umol} / \mathrm{ml}$. In the postoperative period, in patients of group I, cortisol was $478.3 \mathrm{nmol} / 1$ and $368.6 \mathrm{nmol} / 1$ in patients of group II, insulin indicators in group I were $9.2 \mathrm{umol} / \mathrm{ml}$ in group II and $8.4 \mathrm{umol} / \mathrm{ml}$.

When using isolated regional anesthesia, a significant relation between the indicator of situational anxiety, cortisol concentration this indicator amounted to $r=0.7 ; p=0.00006$ in group I and in group II $r=0.6 ; p=0.002$, insulin concentration and the insulin resistance index remained in patients this indicator was $r=0.5 ; p=0.001$ in patients of group I. The study allows us to recommend combined regional anesthesia as a method of anesthesia choice, especially in patients with increased anxiety.

\section{Conflict of interests}

The authors declare that they have no conflicts of interest.

\section{References}

[1] Tobin, J. M., Barras, W. P., Bree, S., Williams, N., McFarland, C., Park, C. et. al. (2018). Anesthesia for Trauma Patients. Military Medicine, 183(suppl_2), 32-35. doi: http://doi.org/10.1093/milmed/usy062

[2] Bohuslavska, N. M., Heorhiiants, M. A. (2015). Choice of the method of anesthesia management of traumatological surgeries in young patients. ScienceRise, 7 (4 (12)), 28-35. doi: http://doi.org/10.15587/2313-8416.2015.47374

[3] Gadsden, J., Warlick, A. (2015). Regional anesthesia for the trauma patient: improving patient outcomes. Local and Regional Anesthesia, 8, 45-55. doi: http://doi.org/10.2147/lra.s55322

[4] Shapovalov, A. A. (2017). Klinicheskaya effektivnost sposoba blokady sedalishnogo nerva lateralnym dostupom pri metallosteosinteze perelomov kostei goleni i stopy. Saint Petersburg, 95.

[5] Logvinenko, V V., Shen, N. P. (2015). Sravnitelnaia kharakteristika riskov razvitiia nezhelatelnykh sobytii i kriticheskikh incidentov pri obschei i regionarnoi anestezii. Analiz 6 let klinicheskoi praktiki. Regionarnaya anesteziya i lechenie ostroi boli, IX (2), 22-28.

[6] Voysekhovskiy, D. V., Averyanov, D. A., Schegolev, A. V., Svistov, D. V. (2018). Effect of deep anesthesia on development of post-operative cognitive dysfunction. Messenger of Anesthesiology and Resuscitation, 15 (1), 5-9. doi: http:// doi.org/10.21292/2078-5658-2018-15-1-5-9 
[7] Huo, T., Sun, L., Min, S., Li, W., Heng, X., Tang, L. et. al. (2016). Major complications of regional anesthesia in 11 teaching hospitals of China: a prospective survey of 106,569 cases. Journal of Clinical Anesthesia, 31, 154-161. doi: http:// doi.org/10.1016/j.jclinane.2016.01.022

[8] McIntyre, J. W. R., Finucane, B. T. (2017). Regional Anesthesia Safety. Complications of Regional Anesthesia, 15-40. doi: http://doi.org/10.1007/978-3-319-49386-2_2

[9] Tarabrin, O. A., Suslov, V. V., Fesenko, V. S., Maruhnyak, L. I., Sherbakov, S. S. (2013). Oslozhneniya perefericheskih nevralnyh blokad. Klinichna anesteziologiya ta intensivna terapiya, 1, 106-119.

[10] Allegri, M., Bugada, D., Grossi, P., Manassero, A., Pinciroli, R., Zadra, N. et. al. (2016). Italian registry of complications associated with regional anesthesia (RICALOR). an incidence analysis from a prospective clinical survey. Minerva Anestesiologica, 82 (4), 392-402.

[11] Ovechkin, A. M., Politov, M. E. (2018). Problemy bezopasnosti regionarnoi anestezii na sovremenom etape. Anesteziologiya i reanimatologiya, 63 (1), 9-16.

[12] Steadman, J., Catalani, B., Sharp, C., Cooper, L. (2017). Life-threatening perioperative anesthetic complications: major issues surrounding perioperative morbidity and mortality. Trauma Surgery \& Acute Care Open, 2 (1), e000113. doi: http:// doi.org/10.1136/tsaco-2017-000113

[13] Merry, A. F., Mitchell, S. J. (2018). Complications of anaesthesia. Anaesthesia, 73, 7-11. doi: http://doi.org/10.1111/anae.14135

[14] Bradshaw, P., Hariharan, S., Chen, D. (2016). Does preoperative psychological status of patients affect postoperative pain? A prospective study from the Caribbean. British Journal of Pain, 10 (2), 108-115. doi: http://doi.org/10.1177/ 2049463716635680

[15] Pinto, A., Faiz, O., Davis, R., Almoudaris, A., Vincent, C. (2016). Surgical complications and their impact on patients' psychosocial well-being: a systematic review and meta-analysis. BMJ Open, 6 (2), e007224. doi: http://doi.org/10.1136/bmjopen-2014-007224

[16] Powell, R., Scott, N. W., Manyande, A., Bruce, J., Vögele, C., Byrne-Davis, L. M. et.al. (2016). Psychological preparation and postoperative outcomes for adults undergoing surgery under general anaesthesia. Cochrane Database of Systematic Reviews. doi: http://doi.org/10.1002/14651858.cd008646.pub2

[17] Stark, P. A., Myles, P. S., Burke, J. A. (2013). Development and Psychometric Evaluation of a Postoperative Quality of Recovery Score. Anesthesiology, 118 (6), 1332-1340. doi: http://doi.org/10.1097/aln.0b013e318289b84b

[18] Zagurovskii, V. M. (2014). Stress i ego posledstviya (dogospitalnyj i rannii gospitalnyi etapy). Medicina neotlozhnyh sostoyanii, 7 (62), 11-23.

[19] Strashnov, V. I., Zabrodin, O. N., Mamedov. A. D. et. al. (2015). Preduprezhdenie intraoperacionnogo stressa i ego posledstvii. Saint Petersburg: ELBI-SPb, 160.

[20] Syusyuka, V. G. (2015). Ocenka balansa kortizol/insulin u beremennyh s razlichnym urovnem trevozhnosti. Suchasni medichni tehnologiyi, 1, 65-70.

[21] Kolomachenko, V. I., Krivobok, V. I., Fesenko, V. S. (2010). Predoperaciina ta pislyaoperaciina trivozhnist v ortopedichnih paciyentiv: korelyaciya $\mathrm{z}$ biohimichnimi stres-markerami. Ukrainskii visnik psihonevrologiyi, 18 (2 (63)), 52-56. 